\title{
Ambiguous role of phlorotannins as chemical defenses in the brown alga Fucus vesiculosus
}

\author{
Julia Kubanek ${ }^{1,2, *}$, Sarah E. Lester ${ }^{3}$, William Fenical ${ }^{4}$, Mark E. Hay ${ }^{1}$ \\ ${ }^{1}$ School of Biology, and ${ }^{2}$ School of Chemistry and Biochemistry, Georgia Institute of Technology, Atlanta, \\ Georgia 30332-0230, USA \\ ${ }^{3}$ Department of Ecology, Evolution and Marine Biology, University of California at Santa Barbara, Santa Barbara, \\ California 93106, USA \\ ${ }^{4}$ Center for Marine Biotechnology and Biomedicine, Scripps Institution of Oceanography, University of California at San \\ Diego, La Jolla, California 92093-0204, USA
}

\begin{abstract}
Brown seaweeds (Fucales) produce phlorotannins that are often considered chemical defenses against herbivores. The many correlative and fewer direct tests conducted have shown effects of phlorotannins on herbivore feeding behavior to be variable. In an attempt to clarify the roles of phlorotannins versus other metabolites in defending brown algae, we conducted bioassay-guided fractionation of herbivore-deterrent extracts from the commonly studied brown alga Fucus vesiculosus. Feeding by the amphipods Ampithoe valida and A. longimana and the sea urchin Arbacia punctulata was suppressed by crude and water-soluble extracts of $F$. vesiculosus, but this deterrence was lost following storage or fractionation of the active, water-soluble extract. Phlorotannins in these extracts did not decompose in parallel with the loss of feeding deterrence. F. vesiculosus phlorotannins were fed to herbivores at 3 to $12 \times$ the isolated yield (or 4.2 to $16.8 \%$ of plant dry mass). No herbivore was deterred from feeding by concentrations of 3 or $6 \times$, but $A$. valida (the only test herbivore that readily consumes $F$. vesiculosus in the field) was deterred at $12 \times$ isolated yield. When juvenile $A$. valida were raised on an artificial diet containing $F$. vesiculosus phlorotannins at $3 \times$ isolated yield, the phlorotannin-rich diet significantly enhanced, rather than reduced, amphipod survivorship and growth relative to an equivalent diet without phlorotannins. Females ovulated only on the phlorotannin-rich diet. Compounds other than phlorotannins appear to defend the $F$. vesiculosus populations we investigated, but we were unable to identify these unstable compounds.
\end{abstract}

KEY WORDS: Phlorotannin · Fucus vesiculosus · Chemical defense · Plant-herbivore interaction . Amphipod · Urchin

Resale or republication not permitted without written consent of the publisher

\section{INTRODUCTION}

Phlorotannins from brown algae represent a large and commonly studied class of marine secondary metabolites (reviewed in Steinberg 1992, Targett \& Arnold 1998, Van Alstyne et al. 2001a). Although phlorotannins are often considered to function as chemical defenses against herbivores, both direct tests (Steinberg 1988, Steinberg \& van Altena 1992, Boettcher \& Targett 1993, Steinberg et al. 1995, Pavia \& Toth 2000, Deal et al. 2003) and correlative experiments (Van Alstyne 1988, Denton \& Chapman 1991,
Steinberg et al. 1991, Tugwell \& Branch 1992, Yates \& Peckol 1993, Targett et al. 1995, Pavia et al. 1997) have shown great variance in the deterrent effects of phlorotannins of brown algae against marine herbivores; e.g. (1) high-molecular weight phlorotannin mixtures $(>10 \mathrm{kDa})$ may affect herbivore physiology while low-molecular weight phlorotannins from the same alga may not (Geiselman \& McConnell 1981, Boettcher \& Targett 1993); (2) some herbivores with acidic guts avoid phlorotannin-rich seaweeds while other herbivores with basic or surfactant-rich digestive tracts readily consume the same seaweeds (Tugwell \& 
Branch 1992, Targett et al. 1995, Targett \& Arnold 1998); (3) effects on herbivores can vary geographically even among herbivores with similar digestive systems: herbivores in temperate Australasia are minimally affected by phlorotannin-rich extracts that deter similar herbivores from the Pacific coast of North America (Steinberg \& van Altena 1992, Steinberg et al. 1995).

Differences in digestive physiology and evolutionary experience with phlorotannins may account for much of the among-herbivore variance in phlorotannin effects, but differences in the structures of the phlorotannins found among algae species and populations also contribute to variable effects and make it difficult to construct general paradigms for phlorotannin-mediated plant-herbivore interactions. Phlorotannins may also possess primary metabolic functions, for example contributing to cell wall structure and reproduction, which could lead to misinterpretation of data testing ecological theories of chemical defense (Arnold \& Targett 2003). Similar difficulties have restricted generalizations about the function of terrestrial plant tannins, which were originally proposed to act as digestibility reducers that few herbivores could tolerate (Feeny 1976), but which were later found to occasionally act as toxins and, in other cases, to be tolerated or even to stimulate some grazers (reviewed in Bernays et al. 1989).

Due to their polarity and polymeric structure, phlorotannins are difficult to separate, purify and characterize. Thus, biologists have commonly used colorimetric assays such as the Folin-Denis (Folin \& Denis 1915), Folin-Ciocalteu (Waterman \& Mole 1994), or 2,4-dimethoxybenzaldehyde (DMBA) (Stern et al. 1996a) assays to measure total phlorotannins, without considering their molecular size, structure, or demonstrated bioactivity (e.g. Van Alstyne \& Pelletreau 2000, Hemmi \& Jormalainen 2002, Norderhaug et al. 2003). The convenience of measuring total phlorotannins as a proxy for 'defense' is counteracted by numerous demonstrations that some phlorotannins depress herbivore assimilation while others do not (e.g. Boettcher \& Targett 1993), that certain phlorotannin mixtures deter feeding by some herbivores but not others (e.g. Steinberg et al. 1995), and that herbivore digestive efficiency or willingness to feed on seaweeds may be either related to (e.g. Steinberg 1985, Denton \& Chapman 1991) or unrelated (e.g. Steinberg et al. 1991, Targett et al. 1995) to the concentrations of phlorotannins in seaweeds.

The first demonstration that phlorotannins of brown algae could function as chemical defenses against herbivores used bioassay-guided fractionation of deterrent extracts from Fucus vesiculosus to show that phlorotannins deterred snail feeding (Geiselman \&
McConnell 1981). Deterrent activities were also detected in other fractions, but these fractions were not chemically investigated. Two decades later, Deal et al. (2003) used bioassay-guided separations to detect a deterrent galactolipid in $F$. vesiculosus; additional deterrent metabolites were also apparent, but were not identified. Thus, phlorotannin-producing seaweeds like F. vesiculosus can produce defensive metabolites other than phlorotannins (see also Steinberg \& van Altena 1992), but these other metabolites have been largely uninvestigated. These deterrent metabolites may be inadequately investigated by ecologists because of the previous focus on phlorotannins, because these compounds are unstable or chemically intractable using standard methodologies, and/or because they are found at very low concentrations in plant tissues relative to phlorotannins (e.g. Kubanek et al. 2003). In this study, we explore the possibility that unrecognized defensive metabolites co-occur with phlorotannins, and may confound assays focused on phlorotannins alone.

This study asked the following questions: (1) How do extracts of Fucus vesiculosus from New England and North Carolina affect feeding by the 2 herbivorous amphipods Ampithoe valida and A. longimana and the sea urchin Arbacia punctulata? (2) If extracts are deterrent, is this due to phlorotannins or to other compounds? (3) If other compounds function as defenses, what are these compounds? (4) How do phlorotannins from $F$. vesiculosus affect herbivore feeding when presented in foods at high concentrations? (5) How do $F$. vesiculosus phlorotannins affect the fitness of herbivorous amphipods raised from birth on a phlorotannin-rich versus phlorotannin-free diet?

\section{MATERIALS AND METHODS}

Organisms and study sites. Fucus vesiculosus is an intertidal brown alga (Fucales) that occurs in the western Atlantic from the Canadian Arctic to North Carolina (Schneider \& Searles 1991). F. vesiculosus and congeneric species have been the focus of many correlative and experimental studies on phlorotanninbased algal chemical defenses (see Ragan \& Glombitza 1986, Steinberg 1992, Van Alstyne et al. 2001a for reviews). Thus, F. vesiculosus is among the best current examples of well-studied seaweeds that use phlorotannin-based chemical defenses. Differences in phlorotannin molecular size, structural distribution, and total concentration ( 0.1 to $15 \%$ of alga dry mass) have been reported for this species (Ragan \& Glombitza 1986, Boettcher \& Targett 1993).

The seaweeds used in our assays were collected from the intertidal zone at Beaufort, North Carolina 
$\left(34^{\circ} 43^{\prime} \mathrm{N}, 76^{\circ} 41^{\prime} \mathrm{W}\right)$, and Avery Point, Connecticut $\left(41^{\circ} 19^{\prime} \mathrm{N}, 72^{\circ} 04^{\prime} \mathrm{W}\right), \mathrm{USA}$. Whole plants were brought to the laboratory in seawater, blotted dry, and frozen or extracted fresh. Frozen plant material used for extraction was thawed and its volume measured by displacement in methanol. Conversion of plant volume to dry mass was determined by freeze-drying a known volume of Connecticut Fucus vesiculosus $(\mathrm{n}=10)$ and determining the dry mass/volume relationship. At Beaufort, 5 collections were made: January 1996 (830 ml, frozen), October 16, 1998 (350 ml, frozen), November 16, 1998 (300 ml, fresh), November 18, 1998 (50 ml, fresh), December 5, 1998 (400 ml, fresh). At Avery Point, 2 collections were made: October 21, 1998 (925 ml, frozen) and December 7, 1998 (1000 ml, frozen).

Feeding preference bioassays were performed with the herbivorous amphipods Ampithoe valida and A. longimana and the sea urchin Arbacia punctulata. Amphipods were originally collected from seaweeds found near Beaufort, and then maintained on various fresh seaweeds in culture in the laboratory. A. punctulata were collected at Radio Island Jetty, Beaufort, and maintained in aquaria at 20 to $22^{\circ} \mathrm{C}$ on fresh Ulva sp. and Enteromorpha sp. with flowing natural seawater.

The herbivorous amphipod Ampithoe valida is a common mesograzer on Fucus vesiculosus and readily consumes this seaweed in both the laboratory and field (Deal 1997, Cruz-Rivera \& Hay 2000). In contrast, Ampithoe longimana and the sea urchin Arbacia punctulata were chosen to represent generalist herbivores (Hay et al. 1986, 1987, Duffy \& Hay 1991, 1994, CruzRivera \& Hay 2001) that do not typically co-occur in the same microhabitat as F. vesiculosus. A. longimana is relatively uncommon on $F$. vesiculosus at the sites we investigated (M. Deal, E. Cruz-Rivera \& E. Sotka pers. comm.), but readily eats subtidal brown algae (Fucales and Dictyotales) (Hay et al. 1987, Duffy \& Hay 1991), including F. vesiculosus in laboratory studies (CruzRivera \& Hay 2001). Its scarcity on $F$. vesiculosus is due to this alga's intertidal distribution; if $F$. vesiculosus plants are moved into the subtidal zone, they are colonized by A. longimana (J. K. \& S. L. unpubl.). Likewise, A. punctulata is primarily found in the subtidal zone and thus does not usually encounter $F$. vesiculosus in the field. A. punctulata is also a good test herbivore because its feeding preferences are similar to those of local omnivorous fishes (which have access to F. vesiculosus at high tide), and several brown algal metabolites that deter fishes also deter these urchins (Hay et al. 1987, 1988, Cronin \& Hay 1996). These similarities suggest that reactions of $A$. punctulata to algal chemical defenses could be a proxy for reactions of other generalist consumers. Lastly, because amphipods and other mesograzers use seaweeds as hiding places from their predators, they sometimes are resistant, or even attracted, to seaweed compounds that deter larger consumers (Hay et al. 1987, Duffy \& Hay 1994, Hay \& Fenical 1996). This provides an interesting opportunity for contrasting the effects of $F$. vesiculosus chemical defenses against a macro-herbivore versus 2 mesograzers.

Feeding assays. Agar and seaweed-based test foods for urchins and amphipods were made using the protocol of Hay et al. $(1994,1998)$. Freeze-dried and finely ground Ulva sp. was used as the nutritional base of the artificial food fed to urchins, while similarly treated Enteromorpha sp. was used for food fed to amphipods. When testing lipophilic extracts, these were dissolved in a suitable solvent (e.g. diethyl ether), added to $2.0 \mathrm{~g}$ of freeze-dried, powdered seaweed, with the solvent removed by rotary evaporation. The resulting treated powder was then suspended in deionized water $(8.0 \mathrm{ml})$. If extracts or compounds to be assayed were water-soluble, they were dissolved in the deionized water just before adding the algal powder. The alga and water suspension was then mixed with a $\sim 60^{\circ} \mathrm{C}$ solution of $0.36 \mathrm{~g}$ agar in $10.0 \mathrm{ml}$ deionized water and stirred rapidly. Before cooling, the liquid food was poured into a mold clamped over window-screening (see Hay et al. 1994, 1998); the screen provided a flexible base to which the agar and algal mix adhered. Control food was made in the same way, using the same solvents but without the addition of extracts. The extract or fraction from a $20 \mathrm{ml}$ volume of fresh Fucus vesiculosus was added to $20 \mathrm{ml}$ of artificial food, thus assuring a natural volumetric concentration of extract. However, because the amount of algal powder that could be held in the agar matrix while still allowing the agar to gel properly was only one-third the dry mass/volume of $F$. vesiculosus, our foods held $3 \times$ the natural concentration of extract on an alga dry mass basis.

For each urchin feeding assay, the windowscreening with attached agar and seaweed was cut with a razor blade into 40 strips containing a square of 1 control and 1 treatment food, each approximately $1 \mathrm{~cm}^{2}$ in area and $2 \mathrm{~mm}$ thick. Each replicate consisted of 1 urchin and 1 food strip within a 11 plastic tub with flow-through seawater. Food strips were checked for consumption every $30 \mathrm{~min}$. Herbivores were permitted to feed until about half of either the treatment or control food was consumed, or until $3 \mathrm{~h}$ had passed. Replicates in which less than $10 \%$ of the total available food or more than $90 \%$ of the total available food was consumed were omitted from consideration. As a result, 20 to 30 replicates were usually available for analysis in each assay. Feeding was measured by clearance of food from the window screen grid (64 food-filled squares). Analyses were accomplished using paired, 
directed $t$-tests, with $80 \%$ of statistical power allocated to detection of deterrent effects, and the remaining $20 \%$ power reserved for detection of feeding stimulation (Rice \& Gaines 1994).

Amphipod feeding assays were similar to the urchin assays, except that smaller and thinner food squares were made (36 window-screening units per square, about $0.5 \mathrm{~mm}$ in thickness) by pressing the mixture into the window-screening. Between 3 and 5 conspecific amphipods were used per assay replicate, with 25 to 40 replicates per assay. Data were collected when about half of either food was consumed, or after 16 to $48 \mathrm{~h}$ if feeding was slower. Data were analyzed as for urchin assays.

General chemical methods. Solvents and chemicals were reagent-grade and were used without further purification. Fractionation of extracts was monitored by thin-layer chromatography (TLC) on reversedphase $\left(\mathrm{C}_{18}\right)$ or normal-phase silica gel plates. Phlorotannins were visualized on TLC plates by absorption of UV light $(254 \mathrm{~nm})$ and by the formation of red stains upon heating, after spraying with vanillin in an ethanolic sulfuric acid solution. Nuclear magnetic resonance (NMR) spectroscopy (Varian 300 and $400 \mathrm{MHz}$ instruments) was used to confirm molecular structures. Spectra were recorded in deuterated chloroform, methanol, or water and referenced to the residual light solvent.

Extraction and bioassay-guided fractionation of Fucus vesiculosus extracts. Fresh or thawed samples of $F$. vesiculosus were placed in methanol and homogenized in a blender. During the course of $2 \mathrm{~d}$, each sample of $F$. vesiculosus was extracted using methanol/water (7:3) 3 times, followed by extraction with methanol twice. Extraction was performed in the dark at $-20^{\circ} \mathrm{C}$ under $1 \mathrm{~atm}$ of nitrogen. Extracts were combined and reduced in vacuo. Crude methanolic extracts of $F$. vesiculosus plants from Connecticut or North Carolina were incorporated into agar-based artificial foods at natural volumetric concentration and offered to herbivores. Extracts that deterred feeding were subjected to solvent-partitioning.

Crude extracts were partitioned between water (500 to $1000 \mathrm{ml}$ depending on sample volume) and dichloromethane $(500 \mathrm{ml})$ and these fractions were tested in feeding assays. The water-soluble partition was deterrent, so it was partitioned against ethyl acetate $(500 \mathrm{ml})$. The aqueous extract was initially deterrent, but lost activity after a few days of storage at $-20^{\circ} \mathrm{C}$ in the dark under nitrogen.

In all feeding assays discussed up to this point, we utilized natural volumetric concentrations of extracts and fractions. These concentrations could be low on a per volume basis if our isolation methods were inefficient, if a proportion of the phlorotannins decomposed during extraction, or if the populations of Fucus vesiculosus we investigated contained lower levels of phlorotannins than is typical of the species in general. We therefore decided to test phlorotannins at levels greater than the natural concentrations found in our study populations. Higher concentration assays were expected to improve our ability to detect weak deterrence and also to test for dose-dependent responses. Additionally, the populations we investigated contained phlorotannins at 1 to $4 \%$ of plant dry mass. Other populations of this species and other brown seaweeds produce higher levels (commonly 2 to $10 \%$, a few even higher: Ragan \& Glombitza 1986, Steinberg 1989, Steinberg et al. 1995, Van Alstyne et al. 2001a).

Although volumetric measurements of natural concentrations reasonably predict the concentration of chemical compounds that a consumer may experience per bite, consumers respond not only to deterrent compounds, but also to the nutritional value of the prey containing those compounds (Duffy \& Paul 1992, Hay et al. 1994, Cruz-Rivera \& Hay 2003). Thus, nutritionally rich foods may better mask the effect of a feeding deterrent than nutritionally poor or dilute food. Our assay food contained $0.11 \mathrm{~g} \mathrm{ml}^{-1}$ of palatable alga (Ulva sp. or Enteromorpha sp.), producing a food that hardened well so that food surfaces were not damaged by the physical movement of herbivores (as opposed to their feeding); however, our populations of Fucus vesiculosus contained $3 \times$ more alga mass per volume $\left(0.33 \pm 0.01 \mathrm{~g} \mathrm{ml}^{-1}, \mathrm{n}=10\right)$ than our assay food. This means that the natural volumetric concentrations of extracts in our initial feeding assays were $3 \times$ the natural concentration of alga dry mass.

Purification of phlorotannins. To obtain purified phlorotannins, Fucus vesiculosus from Connecticut (1000 ml, December 7, 1998) was extracted as described earlier and partitioned between dichloromethane, ethyl acetate, and water; the phlorotannins occurred in the ethyl acetate and water partitions. The ethyl acetate-soluble materials were dissolved in acetone/methanol (2:1), loaded atop an Avicel microcrystalline cellulose column $(17 \times 2.5 \mathrm{~cm})$, and 2 fractions were collected: vanillin-reactive substances (indicating phlorotannins) eluting with acetone/methanol (2:1), and methanol-eluting substances without TLC characteristics.

The aqueous Fucus vesiculosus extract was subjected to dialysis (cellulose ester membrane tubing, molecular weight cut-off $1000 \mathrm{Da}$ ). The extract was dissolved in deionized water and pipetted into the dialysis tubing, which was clamped shut, immersed in deionized water, and vigorously stirred at $15^{\circ} \mathrm{C}$ for $1 \mathrm{~h}$. Material that remained inside the tubing was reduced to near-dryness on a Savant Speed-Vac and then adsorbed onto Avicel microcrystalline cellulose. This was loaded onto a cellu- 
lose column $(37 \times 5.0 \mathrm{~cm})$, and fractions were eluted with acetone/methanol (2:1) and then with methanol. As with the ethyl acetate-soluble material, the earlier fraction contained the phlorotannins.

Characterization of phlorotannins. TLC was initially used to identify fractions containing phlorotannins. Percent phlorotannin was calculated from isolated yield by multiplying the mass of the sample $\times$ percent purity (assessed by ${ }^{1} \mathrm{H}$ and ${ }^{13} \mathrm{C}$ NMR spectroscopy). Additionally, 2 colorimetric methods were used: the Folin-Denis assay (Folin \& Denis 1915) modified (Swain \& Hillis 1959, Ragan \& Craigie 1978, Yates \& Peckol 1993) and adapted to small samples (Cronin \& Hay 1996), and the Folin-Ciocalteu assay (Folin \& Ciocalteu 1927, Waterman \& Mole 1994). The Folin-Denis reagent was made according to the method of the Association of Official Analytical Chemists (1970). The Folin-Ciocalteu reagent and phloroglucinol were purchased from Sigma.

Samples to be analyzed by the Folin-Denis method were weighed ( 5 to $7 \mathrm{mg}$ ) and extracted at $0^{\circ} \mathrm{C}$ for $24 \mathrm{~h}$ in $1.00 \mathrm{ml}$ methanol/water (7:3). Two $100 \mu \mathrm{l}$ aliquots of each sample were then added to vials of $8.40 \mathrm{ml}$ water/methanol (9:1) acidified to $\mathrm{pH} 3$ to 4 with acetic acid; 1 vial of each sample was treated with $120 \mathrm{mg}$ of polyvinylpolypyrrolidone (PVPP) (Andersen \& Todd 1968), agitated for $10 \mathrm{~min}$, and then centrifuged and decanted. This procedure with PVPP was repeated 3 times. Folin-Denis reagent $(0.50 \mathrm{ml})$ was added to each vial (1 having been treated with PVPP ['+PVPP'] and the other not ['-PVPP'], for each sample) and, after $3 \mathrm{~min}, 1.00 \mathrm{ml}$ saturated sodium carbonate solution was added and the time recorded as zero. After $20 \mathrm{~min}$, the UV absorbance at $724 \mathrm{~nm}$ was read using a Spectronic 21D UV spectrophotometer. Absorbance (abs) of reacted phlorotannins in each sample was determined as (abs[-PVPP] - abs[+PVPP]). A standard curve was constructed using solutions of phloroglucinol (7 dilutions), which were treated in the same way as test samples. Regression analysis was used to calculate the 'mg phloroglucinol equivalents' in each sample, which was converted into percent total phlorotannins. Results are mean values of $\%$ phlorotannins $\pm 1 \mathrm{SE}$.

Samples analyzed by the Folin-Ciocalteu method were treated very similarly to those analyzed by the Folin-Denis method (Bolser et al. 1998). The FolinCiocalteu method is reported to be less prone to interference from other compounds, and is not generally corrected by a PVPP extraction (Waterman \& Mole 1994). Because PVPP was not used, extracts were not acidified. Instead, a $100 \mu \mathrm{l}$ aliquot of each sample (extracted in $1.00 \mathrm{ml}$ methanol/water [1:1]) was diluted with deionized water $(7.90 \mathrm{ml})$, and Folin-Ciocalteu reagent $(0.50 \mathrm{ml})$ was added to this solution. After waiting $2 \mathrm{~min}$, saturated sodium carbonate solution
$(1.50 \mathrm{ml})$ was added to each vial. Absorbance at $760 \mathrm{~nm}$ was read, after allowing $2 \mathrm{~h}$ for reaction, and compared to a standard curve constructed using phloroglucinol. Phlorotannin measurements using the Folin-Denis and Folin-Ciocalteu methods were compared and no difference exceeding usual experimental error was detected (data not shown).

Purified phlorotannin fractions were subjected to molecular size determination using ultrafiltration. An Amicon 8400 Millipore $400 \mathrm{ml}$ stirred cell was used in conjunction with double layers of YM10 (molecular weight, MW, cut-off 10000 Da) and YM100 (MW $100000)$-regenerated cellulose membrane filters. Triplicate samples (50 to $80 \mathrm{mg}$ ) were dissolved in $50 \mathrm{ml}$ methanol and passed through the stirred cell under nitrogen gas (5 to 20 pounds per square inch) in semidarkness. Material that passed and did not pass through the filters was dried in vacuo and then weighed. ${ }^{1} \mathrm{H}$ and ${ }^{13} \mathrm{C}$ NMR spectroscopy was used to characterize samples smaller and greater than each molecular weight cut-off in order to qualify values with estimates of purity.

Measurement of phlorotannins in assay food. Loss of phlorotannins from, and phlorotannin binding to, foods throughout the course of feeding assays was quantified as follows. Assay foods containing purified phlorotannins $(6 \times$ isolated yield) were removed from assays after $0 \mathrm{~h}$ (i.e. before use in the assay), $1.5 \mathrm{~h}$ (urchin assay), and 6, 12, and 36 h (amphipod assay). These foods $(n=5)$ were extracted and analyzed by the Folin-Ciocalteu method as described above.

Feeding and growth assays using purified phlorotannins. Ethyl acetate- and water-extracted phlorotannins (combined isolated yield of $1.4 \%$ of plant dry mass) were incorporated into agar-based amphipod assay food at $3 \times(4.2 \%$ dry mass $), 6 \times(8.4 \%)$, and $12 \times$ $(16.8 \%)$ isolated yield per dry mass of alga. Urchins were assayed at $3 \times$ and $6 \times$ isolated yield. At $12 \times$ isolated yield, the thicker foods used in the urchin assays did not gel properly and caused food to be dislodged from screens as urchins moved over them, confounding physical damage and feeding, and thus preventing urchins from being assayed at the highest concentration. The assay food used for amphipods allowed greater concentrations to be used because it was pressed more thinly and adhered more readily to the screen. Therefore, amphipods could be assayed at $12 \times$ isolated yield, by reducing the amount of palatable alga by $50 \%$ while the amount of phlorotannins and liquid added remained the same as in the $6 \times$ natural concentration assay - a technique unsuccessful when applied to urchin food.

To assess the long-term effects of consuming phlorotannins, we raised juvenile Ampithoe valida on seaweed-based artificial diets with or without Fucus 
vesiculosus phlorotannins at $3 \times$ their isolated yield (4.2\% of alga dry mass) and monitored their survival, growth, and ovulation over a period of $64 \mathrm{~d}$. Adult female amphipods holding eggs were collected from low-intertidal F. vesiculosus beds in Beaufort, placed in individual petri dishes with seawater and fresh algae, transported to the laboratory at Georgia Institute of Technology, and monitored for release of juveniles from the mother's brood pouch. We obtained juveniles from 20 mothers, allowing for 20 replicates blocked by mother. Experimental treatments consisted of a phlorotannin-rich algal diet, a phlorotannin-free algal diet, and an agar-only diet (starvation control). The algal diets contained a 1:1:1 mixture of finely ground, freeze-dried Gracilaria tikvahiae, Hypnea musciformis and Enteromorpha sp. These seaweeds are generally palatable and A. valida is known to grow and survive well on diets of mixed algae (Cruz-Rivera \& Hay 2001). Phlorotannin-rich diets were prepared by dissolving phlorotannins purified from $F$. vesiculosus $(4.2 \%$ alga dry mass $)$ in $7.0 \mathrm{ml}$ of methanol, adding this to $0.50 \mathrm{~g}$ powdered algae, removing the methanol by rotary evaporation, and mixing the algae with $2.0 \mathrm{ml}$ of distilled water. This was then stirred together with a hot agar solution made of $0.090 \mathrm{~g}$ agar and $2.5 \mathrm{ml}$ of distilled water. The resulting mixture was poured onto the window screen and pressed flat; upon cooling, the mixture congealed and adhered to the screen. Small squares, equally sized across treatments, were then cut and given to the amphipods. Phlorotannin-free treat-

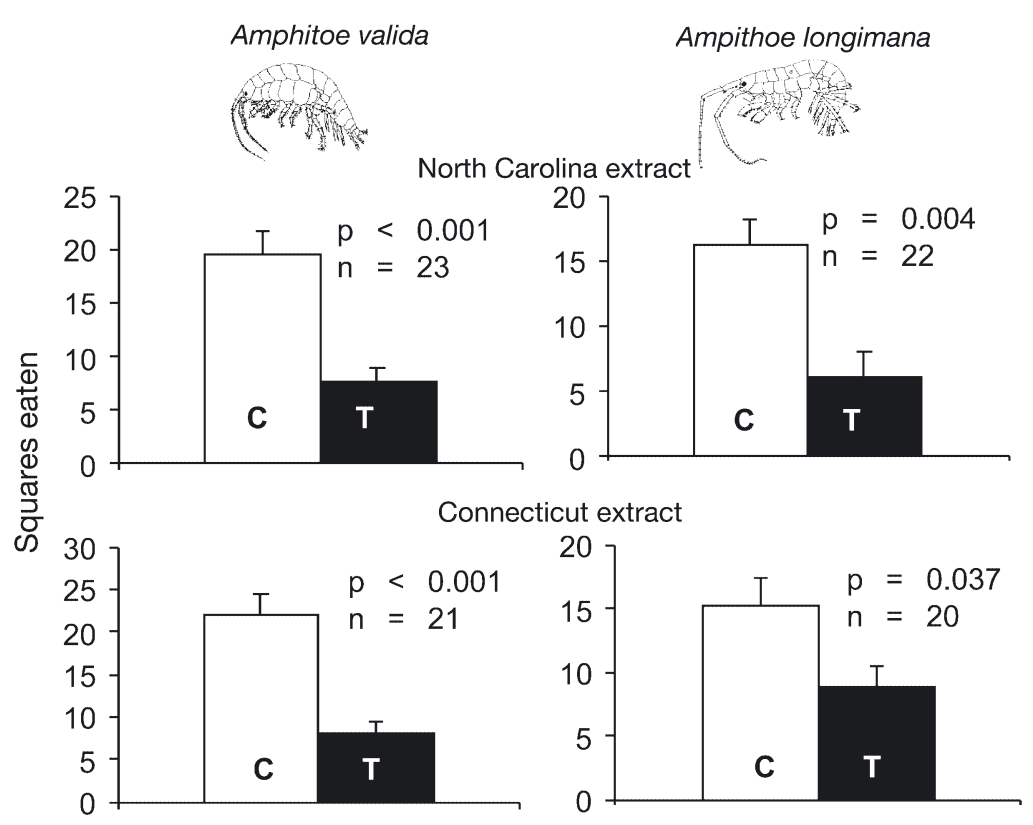

Fig. 1. Ampithoe valida and A. longimana. Effects of Fucus vesiculosus crude extracts on feeding (no. of food squares eaten) by 2 herbivorous amphipods. Data are means +1 SE. C: control; T: treatment ments were produced in an identical fashion, but without addition of the phlorotannins.

Because juveniles from the same mother were assigned at random to each of the 3 treatments, variance within families should have been equally distributed among treatments and each treatment within a block should have started with amphipods of equal size. An equal number of juveniles from each mother was assigned to each treatment within a replicate block. Each replicate block had between 1 and 5 amphipods per treatment dish (i.e. from a mother producing 3 to 25 juveniles). Filtered seawater was replaced, dishes were cleaned, and new experimental food was added to each dish every 2 to $3 \mathrm{~d}$. Amphipods were monitored daily for survivorship and, eventually, reproductive maturity in females. Replicates were started on October 8, 11, and 14, 1999 (Blocks 1 to 5, 6 to 9 and 10 to 20, respectively). The last blocks of experimental treatments were terminated on December 18, 1999 (Day 64), although ovigerous females were killed sooner (Day 52 and 58) so that eggs could be counted and sized. On November 4, 1999 (Blocks 1 to 5 were 26 d old, Blocks 6 to 9 were $23 \mathrm{~d}$ old, and Blocks 10 to 20 were $20 \mathrm{~d}$ old); all surviving amphipods were briefly removed from their dishes and measured from the rostrum to the last large coxa under a microscope. This length measurement was then divided by the amphipod's age in days to determine a growth rate $\left(\mathrm{mm} \mathrm{d}^{-1}\right)$. Comparisons of percent survivorship, number of days survived, and growth were made between the phlorotannin-free and phlorotannin-rich treatments using 2-tailed paired $t$-tests.

\section{RESULTS}

Crude extracts of Fucus vesiculosus populations from both North Carolina and Connecticut consistently deterred feeding by all 3 of our test herbivores, with the deterrent effects being concentrated in the water-soluble fractions (Figs. 1-4). From preliminary work, we knew that Connecticut plants were rich in both ethyl acetateand water-soluble phlorotannins whereas North Carolina plants contained only water-soluble phlorotannins. In order to expose herbivores to the greatest diversity of phlorotannins, we chose to use extracts from the Connecticut plants for further bioassay-guided fractionations in attempts to separate and identify all bioactive compounds. Partitioning of the Connecticut extract between water and dichloromethane produced a deterrent aqueous 


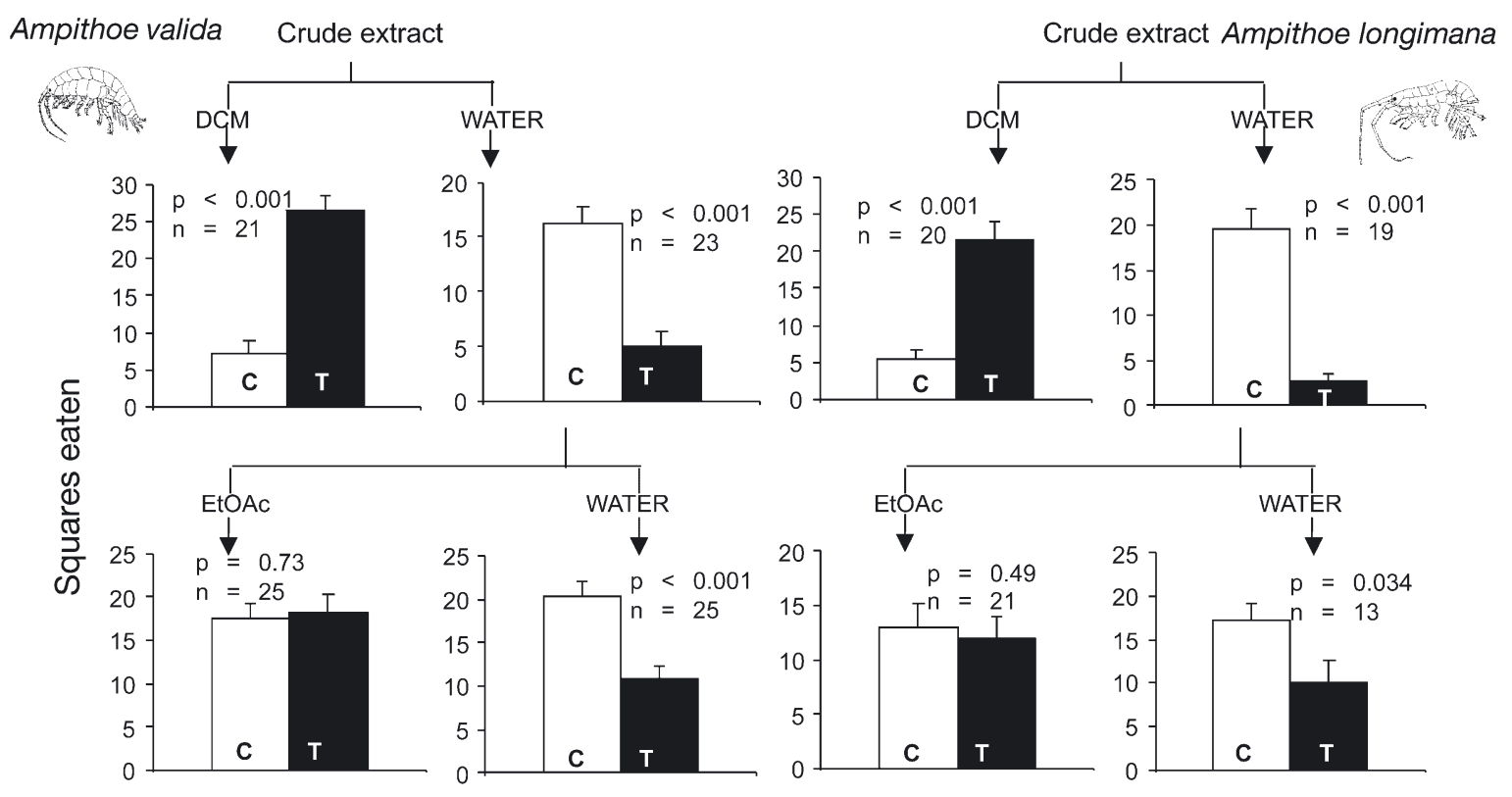

Fig. 2. Ampithoe valida and A. longimana. Effects of solvent partitions of Connecticut Fucus vesiculosus extracts on feeding (no. of food squares eaten) by 2 herbivorous amphipods. DCM: dichloromethane; EtOAc: ethyl acetate. Data are means +1 SE. C: control; T: treatment

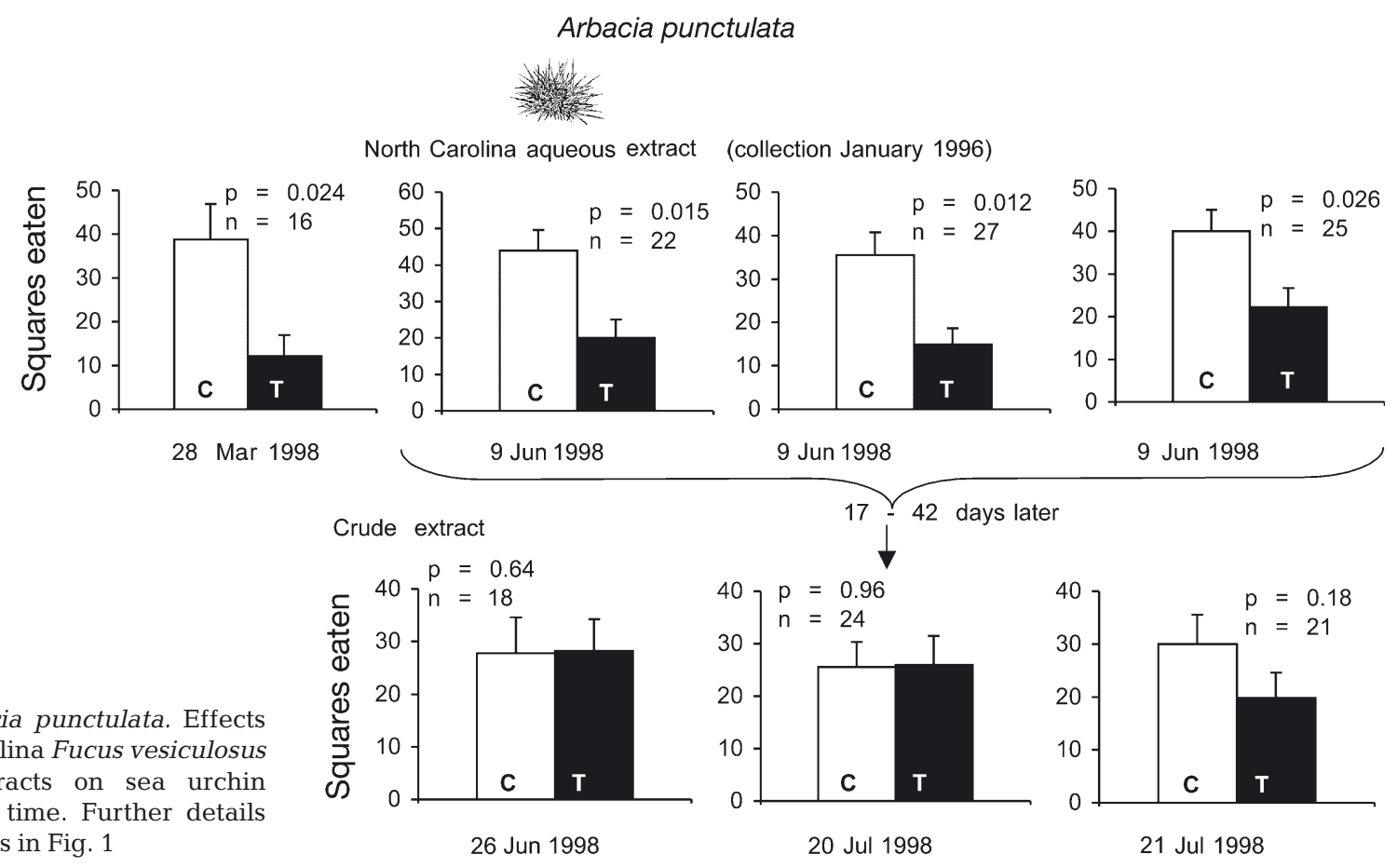

Fig. 3. Arbacia punctulata. Effects of North Carolina Fucus vesiculosus aqueous extracts on sea urchin feeding over time. Further details as in Fig. 1

20 Jul 1998
21 Jul 1998 fraction ( $\mathrm{p}<0.001)$ and a stimulatory dichloromethane fraction $(p<0.001)$, with both species of amphipods showing similar behavior toward the various fractions (Fig. 2). We attempted to identify the compounds stimulating feeding in the dichloromethane fraction, but this activity was unstable, and was lost following short-term storage of the extract (data not shown).

When the deterrent aqueous extract was partitioned between ethyl acetate and water, the ethyl acetate fraction (which contained $0.42 \%$ phlorotannins on a plant dry mass basis) did not affect feeding by either 
Fig. 4. Arbacia punctulata. Effects of solvent partitions of Connecticut Fucus vesiculosus extracts on sea urchin feeding. Further details as in Fig. 2

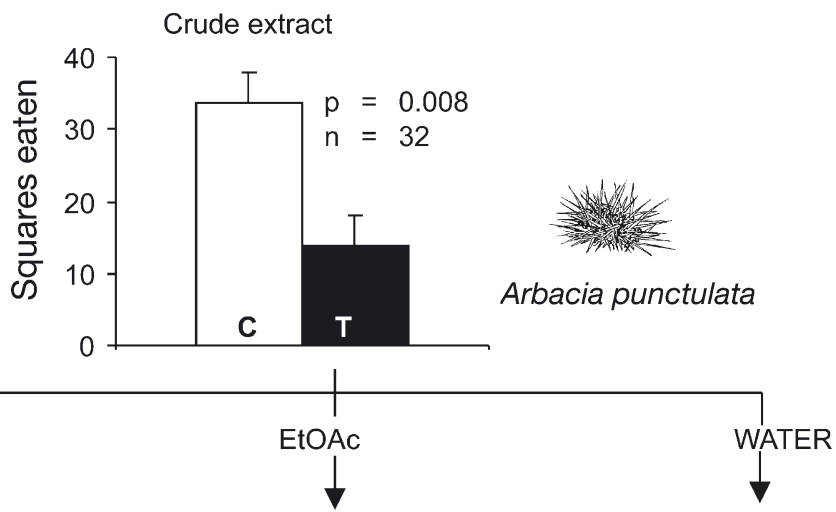

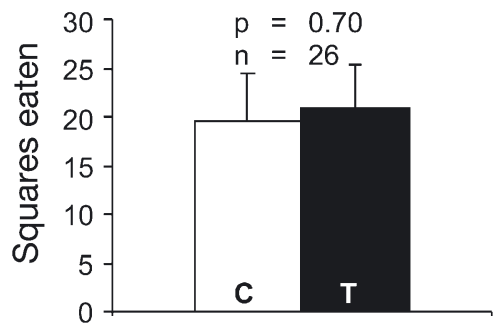
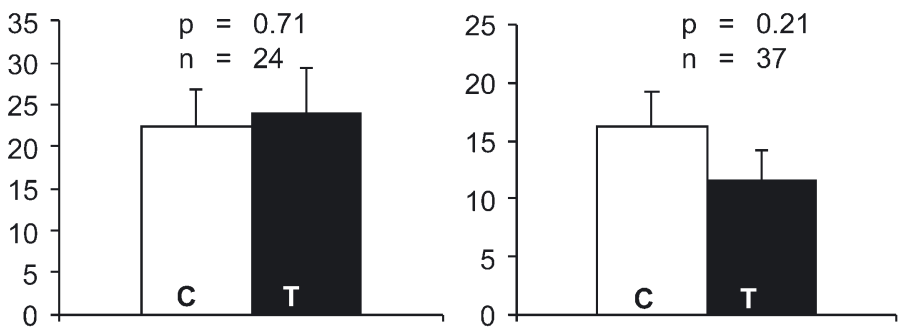

species of amphipod ( $\mathrm{p}=0.73$ and 0.49 for Ampithoe valida and $A$. longimana, respectively), but the aqueous fraction (which contained $0.63 \%$ phlorotannins on a plant dry mass basis) strongly deterred feeding by both: A. valida $=\mathrm{p}<0.001(\mathrm{n}=25) ;$ A. longimana $=\mathrm{p}=$ 0.034 ( $\mathrm{n}=13$ during the first $16 \mathrm{~h}$ of assay). If we included all observations throughout the $40 \mathrm{~h}$ duration of the A. longimana assay, then the feeding deterrence became non-significant $(p=0.13$, mean squares eaten $\pm \mathrm{SE}$, control $=15.0 \pm 1.8$, treatment $=10.9 \pm 2.2, \mathrm{n}=$ 24). This suggests that decomposition or leaching of deterrent metabolites may have occurred during the $40 \mathrm{~h}$ of the assay, but that initial deterrence was strong enough to be statistically detected during the first $13 \mathrm{~h}$. When assayed again 1 wk later, material from the same fraction no longer deterred feeding by $A$. valida $(\mathrm{p}=0.21$, mean squares eaten $\pm \mathrm{SE}$, control $=12.4 \pm$ 1.4 , treatment $=10.3 \pm 7.4, \mathrm{n}=21$ ), suggesting decomposition of active compound(s) during storage despite keeping the material under nitrogen at $-20 \mathrm{C}^{\circ}$ in the dark. At a time midway between the deterrent and the non-deterrent results, Folin-Ciocalteu analysis indicated that phlorotannins in this extract equaled $1.1 \%$ of plant dry mass.

Assays using amphipods required 16 to $40 \mathrm{~h}$ for measurable feeding to occur, and the artificial foods needed to be very thin so that the limited feeding by these small herbivores could be quantified reliably. The long duration of assays and the high surface-tovolume ratio of foods could have compromised our ability to assay unstable or water-soluble metabolites because such compounds might dissolve rapidly from these foods or decompose during the $40 \mathrm{~h}$ assay. In contrast, sea urchins eat more food and eat it faster. Thus, foods made for urchin assays could be thicker (reducing surface-to-volume ratios and thus potential rates of leaching), and assay times could be shortened to $3 \mathrm{~h}$ or less. For these reasons, we thought assays with sea urchins might prove more useful in investigating the causal agent of unstable or water-soluble deterrents in Fucus vesiculosus extracts.

The aqueous extract from a January 1996 collection of North Carolina Fucus vesiculosus significantly deterred feeding by Arbacia punctulata in several assays ( $p=0.024,0.015,0.012,0.026$, Fig. 3 ) conducted shortly after extraction of plant material that had been kept frozen for 27 to 30 mo following collection. However, this extract lost its deterrent properties following storage at $-20^{\circ} \mathrm{C}$ for 17 to $42 \mathrm{~d}(\mathrm{p}=0.64,0.94,0.18$, Fig. 3). Similarly, an October 21, 1998 collection of $F$. vesiculosus from Connecticut produced a deterrent crude extract ( $p=0.008$, Fig. 4$)$, but this deterrence was lost when the extract was partitioned between dichloromethane, ethyl acetate and water $(p=0.21$ to 0.71, Fig. 4), suggesting that the deterrent metabolites in this extract degraded during the separation procedures. These efforts were repeated, producing similar results. Additionally, when the fractions were recombined to reconstitute the crude extract, this was no longer deterrent (data not shown). The loss of deterrence was thus due to decomposition rather than the active metabolite being split among multiple fractions.

The chemical properties of aqueous extracts that deterred urchin feeding were compared with those of 
stored extracts that had lost deterrent activity to see if we could identify chemical changes that might be responsible for the altered biological activity. Colorimetric assays indicated that the North Carolina aqueous extract from the January 1996 collection had similar phlorotannin levels before and after deterrence was lost $(0.32$ and $0.28 \%$ of plant dry mass, respectively). NMR spectral analysis of these deterrent and nondeterrent aqueous extracts indicated no observable difference in the presence or intensity of signals attributable to phlorotannins or to carbohydrates apparent in the samples, suggesting that the loss of deterrence was caused by decomposition of minor component(s).

Folin-Ciocalteu analysis indicated that North Carolina plants contained $3.5 \pm 0.4 \%$ phlorotannins by plant dry mass while those from Connecticut contained $2.7 \pm 0.3 \%(n=6)$. Despite these somewhat similar concentrations of total phlorotannins, TLC and NMR spectral analysis indicated that there were marked chemical differences between the phlorotannins in ethyl acetate extracts of North Carolina versus Connecticut Fucus vesiculosus. These differences were consistent for 2 collections from each area (North Carolina October and November 1998, and Connecticut October and December 1998). F. vesiculosus from Connecticut yielded a substantial ethyl acetate extract rich in phlorotannins ( 0.29 to $0.52 \%$ of plant dry mass), while North Carolina ethyl acetate extracts were negligible in mass and phlorotannin content $(<0.001 \%$ of plant dry mass). In assays run together with replicates interspersed, neither of these extracts deterred urchin feeding and the results of these 2 assays were not significantly different from each other (mean squares eaten \pm SE: North Carolina control $=25.3 \pm 5.7$, treatment $=$ $30.0 \pm 5.2, \mathrm{n}=23 ; \mathrm{p}=0.85$; Connecticut data control $=$ $22.3 \pm 4.5$, treatment $=23.9 \pm 5.4 ; \mathrm{n}=24 ; \mathrm{p}=0.71 ; \mathrm{p}=$ $0.32,2$-tailed $t$-test comparing proportion of treatment and control foods eaten between 2 assays). In contrast to the differences seen for the composition of ethyl acetate-soluble phlorotannins, aqueous extracts of F. vesiculosus from the 2 locations (North Carolina October, 1998, and Connecticut October, 1998) contained similar concentrations of phlorotannins $(0.71$ and $0.63 \%$ of plant dry mass for North Carolina and Connecticut, respectively). Neither extract deterred urchin feeding and the results of the 2 assays were not significantly different from each other (mean squares eaten \pm SE: North Carolina control $=16.9 \pm 3.7$, treatment $=14.4 \pm 3.1, \mathrm{n}=34 ; \mathrm{p}=0.43$; Connecticut control $=16.2 \pm 3.1$, treatment $=11.5 \pm 2.8, \mathrm{n}=37 ; \mathrm{p}=0.21 ; \mathrm{p}=$ $0.44,2$-tailed $t$-test comparing proportion treatment and control foods eaten between 2 assays). The isolated yields of phlorotannins from North Carolina and Connecticut represented only 20 to $43 \%$ of the total phlorotannins predicted to be present in these plants by the Folin-Ciocalteu assay. This loss was likely due to a combination of error in the Folin-Ciocalteu determination using phloroglucinol as a standard (e.g. Hagerman \& Butler 1989, Van Alstyne 1995, Stern et al. 1996a), incomplete extraction, and some decomposition during purification, all of which could have affected feeding responses by herbivores. Therefore, it became important to test isolated phlorotannins at elevated concentrations to compensate for potential loss.

To perform assays with elevated levels of phlorotannins, phlorotannins were purified from both the water- and ethyl acetate-soluble extracts of Connecticut Fucus vesiculosus. NMR spectral analysis of purified ethyl acetate-extracted phlorotannins revealed a complex mixture of phloroglucinol derivatives $\left({ }^{1} \mathrm{H}\right.$ NMR $\delta 5.8$ to $6.4 \mathrm{ppm}^{13} \mathrm{C}$ NMR $\delta 94$ to 103, 122 to $130,150$ to $164 \mathrm{ppm})$. There were no other signals in the ${ }^{13} \mathrm{C}$ NMR spectrum, and only very weak impurity signals at $\delta 1.2$ to $1.6 \mathrm{ppm}$ in the ${ }^{1} \mathrm{H}$ NMR spectrum, suggesting that the ethyl acetate-soluble phlorotannins were $>95 \%$ pure, therefore comprising approximately $0.52 \%$ of plant dry mass. Molecular size determination using ultrafiltration indicated that phlorotannins in this fraction were distributed across a broad molecular weight range: $10 \%$ were measured $<10000 \mathrm{Da}, 72 \%$ were 10000 to $100000 \mathrm{Da}$ and $18 \%$ were $>100000$ Da in size.

NMR spectral analysis of phlorotannins purified from aqueous extracts indicated trace quantities of mannitol and other carbohydrates plus signals consistent with complex phlorotannin polymers similar to the ethyl acetate material described above, suggesting that this phlorotannin fraction was 80 to $90 \%$ pure, representing approximately $0.90 \%$ of plant dry mass. Ultrafiltration coupled with NMR spectral analysis indicated that phlorotannins with molecular weights $<10000$ Da made up $20 \%$ of this mixture, phlorotannins of 10000 to $100000 \mathrm{Da}$ in size constituted $70 \%$, and those of $>100000$ Da constituted $10 \%$ of the mixture. When combined with the ethyl acetate-extracted phlorotannins, the isolated phlorotannins represented $1.4 \%$ of plant dry mass. Folin-Ciocalteu analysis of whole-plant extracts from this Fucus vesiculosus collection suggested a total of $2.7 \%$ phlorotannins, again representing significant loss or discrepancy between these 2 methods (purification of phlorotannins vs Folin-Ciocalteu analysis).

The ethyl acetate-soluble and water-soluble phlorotannins were combined and assayed for their effects on urchin and amphipod feeding at $3 \times, 6 \times$, or $12 \times$ isolated yield as a proportion of plant dry mass (Fig. 5). At $3 \times(=$ $4.2 \%$ phlorotannins by dry mass $)$ and $6 \times(=8.4 \%$ phlorotannins) isolated yield, no significant effect was observed for any of the 3 herbivores. At $12 \times$ isolated yield (16.8\% phlorotannins), changes in the food tex- 
$3 x$ isolated yield
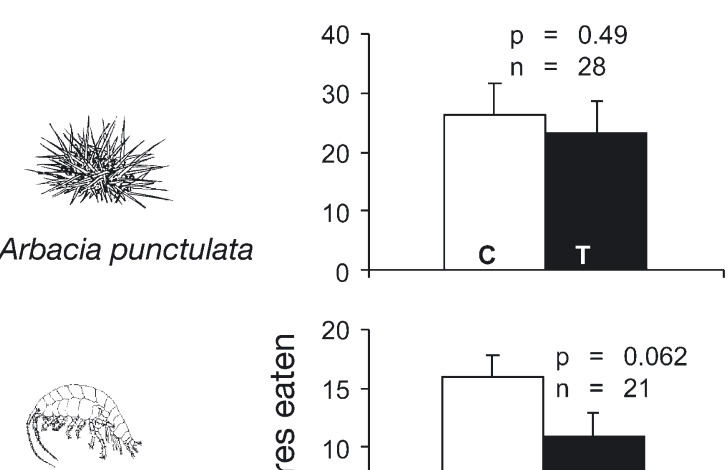

Ampithoe valida

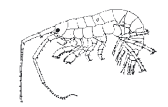

Ampithoe longimana
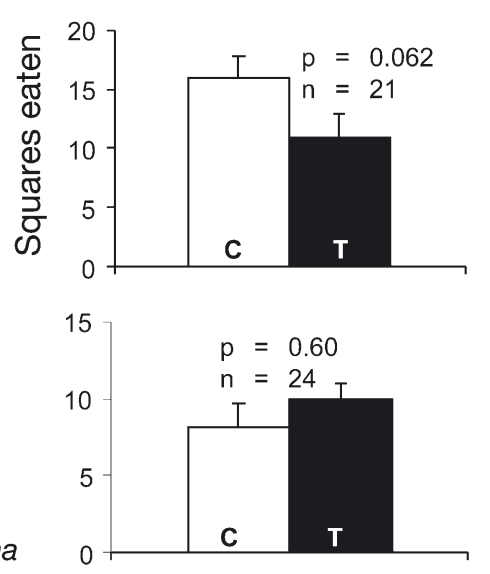

$6 \mathrm{x}$ isolated yield

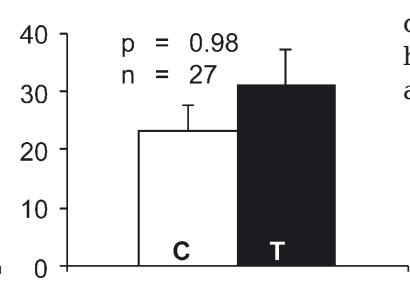

. 5. Ampithoe valida, A. longimana and Arbacia punctulata. Effects of Connecticut Fucus vesiculosus phlorotannins on herbivory by amphipods and sea urchins at various concentrations relative to isolated yield by plant dry mass

$12 \mathrm{x}$ isolated yield
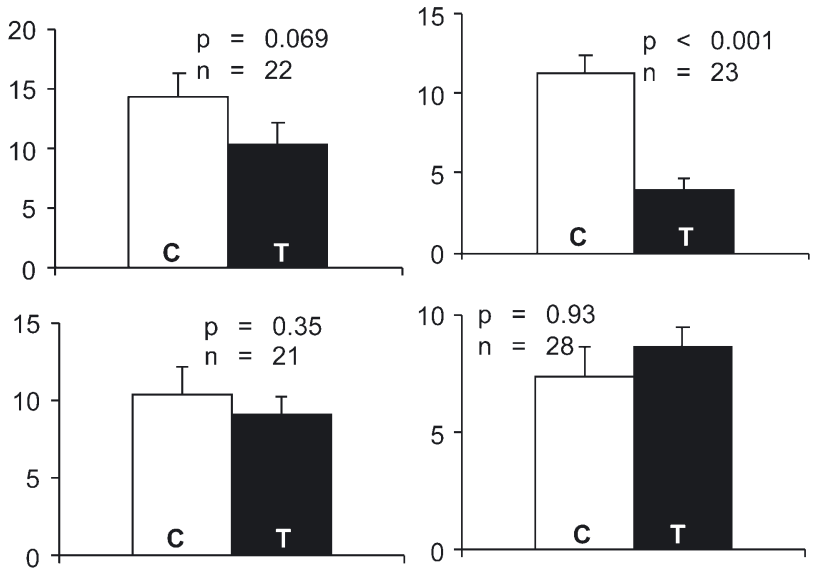

ture prevented urchins from being assayed. At $12 \times$ isolated yield, feeding by the amphipod Ampithoe valida was significantly deterred ( $\mathrm{p}<0.0001)$; feeding by $A$. longimana was unaffected $(\mathrm{p}=0.93)$.

When phlorotannins were added to assay foods and these were immediately re-extracted without being exposed to water, we could extract only about $5 \%$ of the phlorotannins we had just added $(4.7 \pm 0.3 \%$ for the urchin food and $6.5 \pm 0.5 \%$ for the amphipod food, $\mathrm{n}=5$ ). Thus, about $95 \%$ of the phlorotannins appeared to be irreversibly bound to the food. Because all previous behavioral assays demonstrating deterrence of purified phlorotannins also used agar-based foods
(Geiselman \& McConnell 1981, Steinberg 1988, Steinberg \& van Altena 1992, Winter \& Estes 1992), this should have occurred in these earlier assays as well. Furthermore, this finding suggests that it is unlikely that there was significant leaching of phlorotannins during our feeding assays.

Raising Ampithoe valida on an alga-based diet containing Fucus vesiculosus phlorotannins at $3 \times$ their natural yield ( $4.2 \%$ of food dry mass) resulted in significantly enhanced, rather than depressed, survivorship (Fig. 6) and growth (Fig. 7). At Day 29 (approximately the midpoint of our experiment), survivorship was $54 \%$ for amphipods feeding on the phlorotannin-rich diet

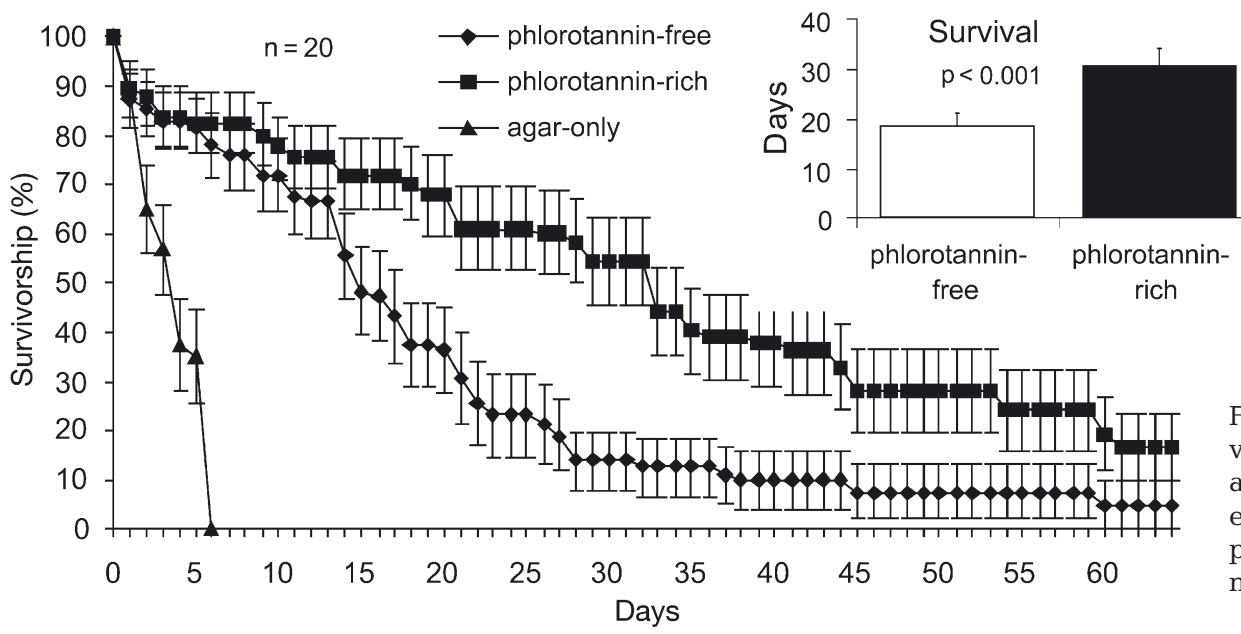

Fig. 6. Ampithoe valida. Survivorship of amphipods raised on artificial diets, averaged within each replicate (1 to 5 amphipods per replicate). Inset: mean number of days survival (calculated on Day 52) 


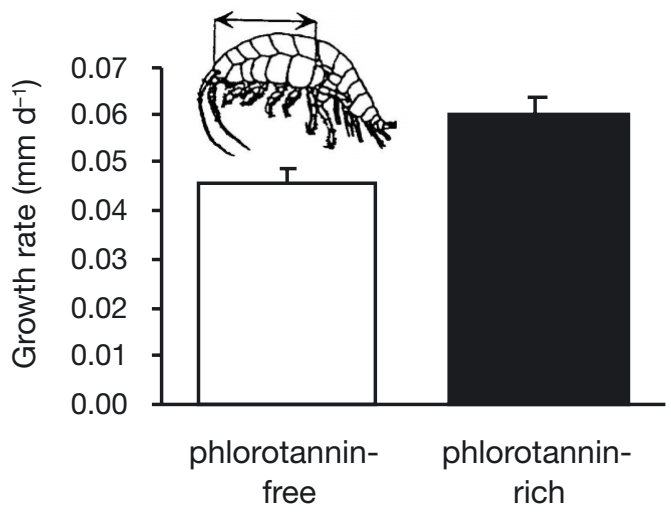

Fig. 7. Ampithoe valida. Growth rates of amphipods raised on artificial diets, paired by common mother, averaged within replicates, measured on Days 20 to 26 (depending on birth date)

and only $14 \%$ for those on the phlorotannin-free diet $(p<0.001)$. By Day 52, when the first female produced eggs, survival was $28 \%$ on the phlorotannin-rich diet and only $8 \%$ on the phlorotannin-free diet $(p=0.023)$. Mean longevity of the amphipods (to Day 52, when the first female was sacrificed to measure eggs) was increased by about $50 \%$ when phlorotannins were added to the diet ( $\mathrm{p}<0.001$, Fig. 6 inset).

When the size of surviving amphipods was measured (on Days 20 to 26 of the experiment, depending on when the mother for each replicate released young, thus allowing the experiment to start), there were 8 diet blocks for which amphipods from the same mother were alive in both phlorotannin-rich and phlorotannin-free treatments, allowing a contrast paired by mother. For these 8 paired replicates, amphipods raised on the phlorotannin-rich diet grew $33 \%$ more than those on an equivalent diet without added phlorotannins (mean of 0.060 vs $0.045 \mathrm{~mm} \mathrm{~d}^{-1}$, paired $t$-test $p=0.003$, Fig. 7). If all growth rate data are included in the analysis (9 replicates with survivors in the phlorotannin-free diet and 17 replicates in the phlorotanninrich treatment), the amphipods on the phlorotanninrich diet show a $26 \%$ higher rate of growth (unpaired $t$-test $\mathrm{p}=0.01$ ). Only 3 females became reproductively mature or ovigerous during the course of the experiment, 2 at Age $53 \mathrm{~d}$ and 1 at Age $59 \mathrm{~d}$. All 3 were raised on the phlorotannin-rich diet.

\section{DISCUSSION}

All 3 species of herbivores were similarly deterred by crude extracts of Fucus vesiculosus, and the pattern and magnitude of deterrence was similar irrespective of whether the seaweeds had been collected from the southern end of the range in North Carolina or the cen- ter of the range in Connecticut (Figs. 1 to 4). However, after the deterrent extracts had been stored frozen for a period of days to weeks, the water-soluble extracts lost their deterrence (Fig. 3, also see Deal et al. 2003). Deterrence was also lost in 1 assay when the crude extract was partitioned between dichloromethane, ethyl acetate, and water (Fig. 4). These changes in palatability were not paralleled by a detectable alteration in phlorotannin concentration or composition, as measured by colorimetric and NMR spectral analyses.

When purified phlorotannins from Connecticut Fucus vesiculosus were assayed at $3 \times$ and $6 \times$ (for Arbacia punctulata) or $3 \times, 6 \times$ and $12 \times$ (for the amphipods) of phlorotannin yield ( $=4.2$ to $16.8 \%$ food dry mass), phlorotannins deterred neither of the herbivores that normally avoid $F$. vesiculosus (A. punctulata and Ampithoe longimana). The herbivore that commonly associates with and eats $F$. vesiculosus in the field (A. valida) was not deterred by $F$. vesiculosus phlorotannins at $3 \times$ or $6 \times$ isolated yield, but $12 \times$ isolated yield $(16.8 \%$ food dry mass) did significantly deter this consumer (Fig. 5). Typical phlorotannin levels for unpalatable brown algae range from 1 to $10 \%$, with only a few exceeding 10 to $15 \%$ (Ragan \& Jensen 1977, 1978, Ragan \& Glombitza 1986, Steinberg 1989, Steinberg \& van Altena 1992, Steinberg et al. 1995). Therefore, our tests were within the ranges of phlorotannin concentrations found in brown algae.

It seems unlikely that our failure to detect deterrence was a result of testing phlorotannins from the smaller size classes, which are suggested to be less active (Steinberg 1988, Steinberg \& van Altena 1992, Boettcher \& Targett 1993). Molecular size determination using ultrafiltration indicated that $90 \%$ of the ethyl acetate-extracted phlorotannins from Connecticut plants were larger than $10000 \mathrm{Da}$, with $18 \%$ having molecular weights $>100000$ Da. The water-extracted phlorotannins were also relatively large: $70 \%$ of the isolated phlorotannins were 10000 to $100000 \mathrm{Da}$, and $10 \%$ were $>100000 \mathrm{Da}$.

Although almost all ecologically realistic assays of chemical defenses against marine herbivores employ behavioral assays like ours (Hay et al. 1998), it is possible that herbivores avoid the physiological consequences of consuming phlorotannins by rejecting plants based upon some non-phlorotannin cue that reliably occurs in phlorotannin-rich seaweeds. If this is the case, then short-term behavioral assays might fail to detect damaging physiological effects that the consumers would experience if they consistently consumed seaweeds producing phlorotannins (see Boettcher \& Targett 1993). To evaluate this possibility, we raised juvenile Ampithoe valida on foods with and without phlorotannins at $3 \times$ isolated yield $(4.2 \%$ of food dry mass). 
Adding purified phlorotannins to foods significantly increased, rather than decreased, the survivorship and growth of these amphipods (Figs. 6 \& 7). Only 3 females produced eggs during the experiment, all from the phlorotannin-rich treatment. The increased growth, survivorship, and possibly reproduction of Ampithoe valida fed phlorotannin-rich diets could have resulted from (1) phlorotannins being used by amphipods as a carbon source, as occurs in some terrestrial grasshoppers and locusts (Bernays \& Chamberlain 1980, Bernays \& Woodhead 1982); (2) phlorotannins reducing the negative effects of pathogenic agents, as has been shown for gypsy moths feeding on hydrolysable tannins (Schultz et al. 1990); (3) phlorotannins complexing and therefore reducing deleterious effects of other compounds from algae used to make the artificial diet (Gracilaria tikyahiae, Hypnea musciformis and Enteromorpha sp. - these are not known to contain toxins but this has not been extensively studied), as has been hypothesized to occur with terrestrial tannins consumed by vertebrates that feed on alkaloid- and saponin-rich plants (reviewed in Bernays et al. 1989); (4) phlorotannins increasing the retention of dietary proteins, as occurs in some ruminants in which binding of terrestrial tannins to dietary proteins appears to prevent protein deamination by gut microbes (reviewed in Bernays et al. 1989) (however, this has not been shown to occur in marine invertebrates); (5) other unknown mechanisms. The current study could not distinguish among these alternative possibilities, but investigations of how plant defensivemetabolites might sometimes serve as medicinal or nutritional agents seem warranted due to the accumulating examples of positive effects of metabolites otherwise thought to act as feeding deterrents (Bernays \& Chamberlain 1980, Bernays \& Woodhead 1982, Bernays et al. 1989, Schultz et al. 1990; see also CruzRivera \& Hay 2003 for data on the isopod Paracerceis caudata cultured on brown algae diterpenes). There are now numerous marine examples of consumers whose feeding is not deterred by phlorotannins (Steinberg \& van Altena 1992, Steinberg et al. 1995, Targett et al. 1995, Jormalainen et al. 2001, Deal et al. 2003), and there are various testable hypotheses about how gut physiology and other herbivore traits may allow specific consumers to tolerate phlorotannins (Targett \& Arnold 1998). To our knowledge, however, the present study comprises the first example of a marine herbivore whose fitness is significantly enhanced by the consumption of phlorotannins.

In this study, feeding assays were conducted using agar-based foods, as in all previous investigations that have directly shown phlorotannins to act as chemical defenses that decrease feeding by some herbivores (Geiselman \& McConnell 1981, Steinberg 1988, Stein- berg \& van Altena 1992, Winter \& Estes 1992, Steinberg et al. 1995, Pavia \& Toth 2000). We were concerned that phlorotannins might leach from the agar into the surrounding seawater and be lost from treatment foods during the assay. However, 95\% of the phlorotannins added to our foods did not leach out and could not be re-extracted, even with methanol. Additionally, because our initial amphipod assays with crude extracts ran for $48 \mathrm{~h}$ and documented strong deterrence, it is unlikely that the active compounds were typically lost from the foods over a $48 \mathrm{~h}$ test period.

The binding of phlorotannins to agar-based foods could be a methodological problem or a solution, depending on how phlorotannins act within consumers - when they do so. If polyphenolic compounds, including phlorotannins, act by complexing dietary proteins and lowering assimilation or digestibility of these nutrients, as suggested by numerous studies (Feeny 1976, Swain 1979, see marine example provided by Boettcher \& Targett 1993), then the complexation occurring in our artificial foods mirrored natural effects. However, if they act as toxins, or by binding the consumer's digestive enzymes, or in other ways (Bernays et al. 1989, Stern et al. 1996b), then by prebinding them in our food, anti-herbivore mechanisms of action may have been prevented. However, all of the published reports that have directly shown feeding deterrence due to phlorotannins have used agar-based assays (Geiselman \& McConnell 1981, Steinberg 1988, Steinberg \& van Altena 1992, Winter \& Estes 1992, Steinberg et al. 1995, Pavia \& Toth 2000), indicating that phlorotannins in agar can exhibit deterrent effects.

Our assay food differed from previous studies in that our food contained dried algae particles rather than just the water extract of the algae. As such, our foods should have been more nutritionally valuable, and probably more ecologically realistic, than the foods used in most previous assays. Deterrent effects of defensive metabolites vary with the nutritional value of the foods in which they are presented, and compounds that deter feeding in low-value foods may have no effect in higher value foods (Duffy \& Paul 1992, Hay et al. 1994). For example, Bernays and colleagues (reviewed in Bernays 1981) showed that terrestrial tannins were more deterrent when presented to insects in foods lacking plant protein than in foods containing protein.

Previous evidence demonstrating deterrence of phlorotannins came from assays in which the nutritional value of the test food may have been low compared to that of the seaweeds from which the phlorotannins were extracted. As examples, Geiselman \& McConnell (1981) ground fresh palatable algae 
in water, then added this mixture (with the water diluting the algae material) to additional water and agar to make the food in which their algal extracts were tested. Steinberg et al. (1995) and Pavia \& Toth (2000) apparently used similar procedures. Steinberg (1988) ground 1 part fresh palatable alga in 3 parts of water, filtered out the solid alga pieces, and used this flavored water in assay food. Winter \& Estes (1992) used similar procedures. In all these assays, the nutritional value per volume of food would have been very low relative to the original alga. The alga dry mass per volume of our assay food was only $33 \%$ of that in Fucus vesiculosus, but this value would have been higher than that in foods used in previous investigations. However, including dried plant matter or aqueous plant extracts as a nutritional base in assay foods could be problematic, if phlorotannins become bound to plant proteins in assay foods and thus cannot be detected by herbivores. This cannot be avoided unless protein-free foods are used-reducing the ecological meaning of the results.

Although effects of Fucus vesiculosus crude and aqueous extracts on herbivore feeding clearly demonstrate that the seaweed is chemically defended (Figs. 1 to 4), we found no evidence that this defense is based on the behavioral or physiological effects of phlorotannins. Unfortunately, because of decomposition, we were unable to isolate and identify the metabolites that defend this seaweed. However, the similar effects of extracts from both North Carolina and Connecticut populations of $F$. vesiculosus demonstrate that these defenses are not restricted to 1 unusual population. It is conceivable that there was 1 deterrent (but unstable) phlorotannin or small group of phlorotannins that eluded us in the phlorotannin purification process that was responsible for the original deterrence of the crude extracts. Although unlikely, this could be possible if (1) the deterrent phlorotannins were at such low concentration that NMR spectral analysis could not distinguish them against a background of other phlorotannins (since we detected no change in phlorotannin composition by NMR spectral data during the time when activity of the crude extract was being lost), (2) they were more readily decomposed than most other phlorotannins during handling and storage (possible for biologically active compounds) but (3) remained active in assay foods for up to $48 \mathrm{~h}$ when tested in crude extracts. Our inability to detect significant effects of $F$. vesiculosus phlorotannins on consumer feeding or physiology (Figs. 5 to 7), even at considerably elevated concentrations, makes it more plausible that phlorotannins from the $F$. vesiculosus populations we studied did not deter feeding.

In a previous study of Fucus vesiculosus collected from the same Beaufort site, Deal et al. (2003) demon- strated that an ethyl acetate-soluble galactolipid and an unidentified non-phlorotannin water-soluble metabolite deterred feeding by Arbacia punctulata. We did not detect the galactolipid in the extracts we analyzed, either by bioassay or by NMR spectroscopy. The differences between our findings and those of Deal et al. (2003) could indicate a temporal pattern of production for this compound or that our differing extraction methods resulted in loss of the compound. Additionally, physical stresses can constrain production or retention of defensive metabolites in seaweeds (Renaud et al. 1990, Cronin \& Hay 1996), and conditions may have differed during the 2 studies. As in our work, Deal et al. (2003) were unable to demonstrate any deterrent effect of phlorotannins from $F$. vesiculosus on urchin feeding behavior, even when tested at 2 to $4 \times$ natural concentration. They attributed part of the deterrence they observed to water-soluble metabolites(s) other than phlorotannins, but were unable to purify and identify the active metabolite(s). Other investigators studying chemical defenses in phlorotannin-producing brown seaweeds report that losing activity following storage or separation of extracts is not uncommon (P. Steinberg \& N. Targett pers. comm.), and thus still-unidentified deterrent compounds may be more common than reflected by the literature. Although the identity and physiological effects of these metabolites cannot be determined until methods are developed for purifying and identifying the active metabolites, ecologists with interests in these areas should be aware of the evidence suggesting that chemical defenses of brown algae may be more diverse than is presently reflected by the literature.

Given that crude and aqueous extracts of Fucus vesiculosus strongly deterred feeding of 3 generalist herbivore species including 1 macro-herbivore and 2 mesograzers, but that these deterrent effects could not be attributed to phlorotannins (Figs. 5 to 7), future studies of variation in chemical defenses (in response to actual or simulated herbivory: e.g. Hammerstrom et al. 1998 and Arnold et al. 2001; in response to variance in nutrients: e.g. Cronin \& Hay 1996, Hemmi \& Jormalainen 2002; across various spatial and temporal scales: e.g. Denton \& Chapman 1991 and Van Alstyne et al. 1999, 2001b) need to confirm that the metabolites being monitored do indeed function as defenses, and that other unrecognized metabolites are not confounding interpretations.

To date, 5 studies have directly tested purified or semi-purified phlorotannins from Fucus vesiculosus on herbivore behavior or physiology (Geiselman \& McConnell 1981, Steinberg 1988, Boettcher \& Targett 1993, Deal et al. 2003, this study), 4 of them employing the same agar-based bioassay design. In these studies, 5 herbivores (1 fish, 3 snails, and 1 echinoderm) were 
negatively affected by at least some mixtures of phlorotannins at natural, or close to natural, concentrations (Geiselman \& McConnell 1981, Steinberg 1988, Boettcher \& Targett 1993), and 3 herbivores (2 amphipods and 1 echinoderm) were undeterred (Deal et al. 2003, present study). We suggest that in addition to the possibility of phlorotannin structure, herbivore gut environment, and biogeographical effects mediating the role of phlorotannins in brown seaweeds, polar and unstable, but strongly deterrent, metabolites other than phlorotannins may be a confounding factor in identifying the chemical defenses of brown algae. We suggest that measurements of total phlorotannins will often provide little insight into the chemical defenses of brown algae, and call for the development of new approaches in the hope of being able to identify the deterrents that play an ecological role in defending Fucus vesiculosus and possibly other brown seaweeds.

Acknowledgements. This work was supported by NSF grant OCE-95-29784 to M.E.H. with additional support from the Harry and Linda Teasley endowment to Georgia Institute of Technology, by NSF grant CHE-98-07098 to W.F., and by an NSERC (Canada) post-doctoral fellowship to J.K. We thank C. Kicklighter, J. J. Stachowicz, P. Brown, and S. Wear for performing additional feeding assays, and E. E. Sotka and R. Taylor for sorting and identifying amphipods. J. J. Stachowicz also provided Fucus vesiculosus from Connecticut. We are grateful to A. Boettcher for information about performing size-determination assays of phlorotannin samples. The comments of N. M. Targett and 2 diligent reviewers substantially improved this manuscript.

\section{LITERATURE CITED}

Andersen RA, Todd JR (1968) Estimation of total tobacco plant phenols by their bonding to polyvinylpyrrolidone. Tob Sci 12:107-111

Arnold TM, Targett NM (2003) To grow and defend: lack of tradeoffs for brown algal phlorotannins. Oikos 100: 406-408

Arnold TM, Targett NM, Tanner CE, Hatch WI, Ferrari KE (2001) Evidence for methyl jasmonate-induced phlorotannin production in Fucus vesiculosus (Phaeophyceae). J Phycol 37:1026-1029

Association of Official Analytical Chemists (AOAC) (1970) Official methods of analysis of the AOAC. AOAC, Washington, DC

Bernays EA (1981) Plant tannins and insect herbivores: an appraisal. Ecol Entomol 6:353-360

Bernays EA, Chamberlain DJ (1980) A study of tolerance of ingested tannin in Schistocerca gregaria. J Insect Physiol 26:415-420

Bernays EA, Woodhead S (1982) Plant phenols utilized as nutrients by a phytophagous insect. Science 216:201-202

Bernays EA, Driver GC, Bilgener M (1989) Herbivores and plant tannins. Adv Ecol Res 19:263-302

Boettcher AA, Targett NM (1993) Role of polyphenolic molecular size in reduction of assimilation efficiency in Xiphister mucosus. Ecology 74:891-903

Bolser RC, Hay ME, Lindquist N, Fenical W, Wilson D(1998)
Chemical defenses of freshwater macrophytes against crayfish herbivory. J Chem Ecol 24:1639-1658

Cronin G, Hay ME (1996) Effects of light and nutrient availability on the growth, secondary chemistry, and resistance to herbivory of 2 brown seaweeds. Oikos 77:93-106

Cruz-Rivera E, Hay ME (2000) The effects of diet mixing on consumer fitness: macroalgae, epiphytes, and animal matter as food for marine amphipods. Oecologia 123: $252-264$

Cruz-Rivera E, Hay ME (2001) Macroalgal traits and the feeding and fitness of an herbivorous amphipod: the roles of selectivity, mixing, and compensation. Mar Ecol Prog Ser 218:249-266

Cruz-Rivera E, Hay ME (2003) Prey nutritional quality interacts with chemical defenses to affect consumer feeding and fitness. Ecol Monogr 73:483-506

Deal MS (1997) The causes and consequences of withinspecies variation in seaweed chemical defenses. $\mathrm{PhD}$ thesis, University of North Carolina at Chapel Hill

Deal MS, Hay ME, Wilson D, Fenical W (2003) Galactolipids rather than phlorotannins as herbivore deterrents in the brown seaweed Fucus vesiculosus. Oecologia 136: $107-114$

Denton A, Chapman ARO (1991) Feeding preferences of gammarid amphipods among four species of Fucus. Mar Biol 109:503-506

Duffy JE, Hay ME (1991) Food and shelter as determinants of food choice in an herbivorous marine amphipod. Ecology $72: 1286-1298$

Duffy JE, Hay ME (1994) Herbivore resistance to seaweed chemical defense: the roles of mobility and predation risk. Ecology 75:1304-1319

Duffy JE, Paul VJ (1992) Prey nutritional quality and the effectiveness of chemical defenses against tropical reef fishes. Oecologia 90:333-339

Feeny P (1976) Plant apparency and chemical defense. Recent Adv Phytochem 10:1-40

Folin O, Ciocalteu V (1927) On tyrosine and tryptophane determinations in proteins. J Biol Chem 73:627-650

Folin O, Denis W (1915) A colorimetric method for the determination of phenols (and phenol derivatives) in urine. J Biol Chem 22:305-308

Geiselman JA, McConnell OJ (1981) Polyphenolics in brown algae Fucus vesiculosus and Ascophyllum nodosum: chemical defenses against the marine herbivorous snail, Littorina littorea. J Chem Ecol 7:1115-1133

Hagerman AE, Butler LG (1989) Choosing appropriate methods and standards for assaying tannin. J Chem Ecol $15: 1795-1810$

Hammerstrom K, Dethier MN, Duggins DO (1998) Rapid phlorotannin induction and relaxation in five Washington kelps. Mar Ecol Prog Ser 165:293-305

Hay ME, Fenical W (1996) Chemical ecology and marine biodiversity: insights and products from the sea. Oceanography 9:10-20

Hay ME, Lee Jr RR, Guieb RA, Bennett MM (1986) Food preference and chemotaxis in the sea urchin Arbacia punctulata (Lamarck) Philippi. J Exp Mar Biol Ecol 96: $147-153$

Hay ME, Duffy JE, Pfister CA, Fenical W (1987) Chemical defense against different marine herbivores: are amphipods insect equivalents? Ecology 68:1567-1580

Hay ME, Renaud PE, Fenical W (1988) Large mobile versus small sedentary herbivores and their resistance to seaweed chemical defenses. Oecologia 75:246-252

Hay ME, Kappel QE, Fenical W (1994) Synergisms in plant defenses against herbivores: interactions of chemistry, 
calcification, and plant quality. Ecology 75:1714-1726

Hay ME, Stachowicz JJ, Cruz-Rivera E, Bullard S, Deal MS Lindquist, $N$ (1998) Bioassays with marine and freshwater macroorganisms. In: Haynes KF, Millar JG (eds) Methods in chemical ecology, Vol 2. Bioassay methods. Kluwer Academic Publishers, Norwell, MA, p 39-141

Hemmi A, Jormalainen V (2002) Nutrient enhancement increases performance of a marine herbivore via quality of its food alga. Ecology 83:1052-1064

Jormalainen V, Honkanen T, Heikkila N (2001) Feeding preferences and performance of a marine isopod on seaweed hosts: cost of habitat specialization. Mar Ecol Prog Ser 220: 219-230

Kubanek J, Jensen PR, Keifer PA, Sullards MC, Collins DO, Fenical W (2003) Seaweed resistance to microbial attack: a targeted chemical defense against marine fungi. Proc Natl Acad Sci USA 100:6916-6921

Norderhaug KM, Fredriksen S, Nygaard K (2003) Trophic importance of Laminaria hyperborean to kelp forest consumers and the importance of bacterial degradation to food quality. Mar Ecol Prog Ser 255:135-144

Pavia H, Toth GB (2000) Inducible chemical resistance to herbivory in the brown seaweed Ascophyllum nodosum. Ecology 81:3212-3225

Pavia H, Cervin G, Lindgren A, Aberg P (1997) Effects of UV$\mathrm{B}$ radiation and simulated herbivory on phlorotannins in the brown alga Ascophyllum nodosum. Mar Ecol Prog Ser 157:139-146

Ragan MA, Craigie JS (1978) Phenolic compounds in brown and red algae. In: Hellebust JA, Craigie JS (eds) Handbook of phycological methods, Vol 2. Cambridge University Press, New York, p 157-179

Ragan MA, Glombitza KW (1986) Phlorotannins, brown algal polyphenols. Prog Phycol Res 4:129-241

Ragan MA, Jensen A (1977) Quantitative studies on brown algal phenols. I. Estimation of absolute polyphenol content of Ascophyllum nodosum (L.) Le Jol. and Fucus vesiculosus (L.). J Exp Mar Biol Ecol 30:209-221

Ragan MA, Jensen A (1978) Quantitative studies on brown algal phenols. II. Seasonal variation in polyphenol content of Ascophyllum nodosum (L.) Le Jol and Fucus vesiculosus (L.). J Exp Mar Biol Ecol 34:245-258

Renaud PE, Hay ME, Schmitt TM (1990) Interaction of plant stress and herbivory: intraspecific variation in the susceptibility of a palatable versus an unpalatable seaweed to sea urchin grazing. Oecologia 82:217-226

Rice WR, Gaines SD (1994) 'Heads I win, tails you lose': testing directional alternative hypotheses in ecological and evolutionary research. Trends Ecol Evol 9:235-237

Schneider CW, Searles RB (1991) Seaweeds of the southeastern United States. Duke University Press, Durham NC

Schultz JC, Foster MA, Montgomery ME (1990) Hostplantmediated impact of pathogens on gypsy moth populations. In: Watt A, Hunter MD (eds) Population dynamics of forest insects. Intercept, London, p 303-313

Steinberg PD (1985) Feeding preferences of Tegula funebralis and chemical defenses of marine brown algae. Ecol Monogr 55:333-349

Steinberg PD (1988) Effects of quantitative and qualitative variation in phenolic compounds on feeding in three species of marine invertebrate herbivores. J Exp Mar Biol Ecol 120:221-237

Steinberg PD (1989) Biogeographical variation in brown algal polyphenolics and other secondary metabolites: comparison between temperate Australiasia and North America.
Oecologia 78:373-382

Steinberg PD (1992) Geographical variation in the interaction between marine herbivores and brown algal secondary metabolites. In: Paul VJ (ed) Ecological roles of marine secondary metabolites. Comstock Publishing Associates, Ithaca, NY, p 51-92

Steinberg PD, van Altena I (1992) Tolerance of marine invertebrate herbivores to brown algal phlorotannins in temperate Australasia. Ecol Monogr 62:189-222

Steinberg PD, Edyvane K, de Nys R, Birdsey R, van Altena IA (1991) Lack of avoidance of phenolic-rich brown algae by tropical herbivorous fishes. Mar Biol 109:335-343

Steinberg PD, Estes JA, Winter FC (1995) Evolutionary consequences of food chain length in kelp forest communities. Proc Natl Acad Sci USA 92:8145-8148

Stern JL, Hagerman AE, Steinberg PD, Winter FC, Estes JA (1996a) A new assay for quantifying brown algal phlorotannins and comparisons to previous methods. J Chem Ecol 22:1273-1293

Stern JL, Hagerman AE, Steinberg PD, Mason PK (1996b) Phlorotannin-protein interactions. J Chem Ecol 22: $1877-1899$

Swain T (1979) Tannins and lignins. In: Rosenthal GA, Janzen DH (eds) Herbivores: their interaction with secondary plant metabolites. Academic Press, New York, p 657-682

Swain T, Hillis WE (1959) The phenolic constituents of Prunus domestica. J Sci Food Agric 10:63-68

Targett NM, Arnold TM (1998) Predicting the effects of brown algal phlorotannins on marine herbivores in tropical and temperate oceans. J Phycol 34:195-205

Targett NM, Boettcher AA, Targett TE, Vrolijk NH (1995) Tropical marine herbivore assimilation of phenolic-rich plants. Oecologia 103:170-179

Tugwell S, Branch GM (1992) Effects of herbivore gut surfactants on kelp polyphenol defenses. Ecology 73:205-215

Van Alstyne KL (1988) Herbivore grazing increases polyphenolic defenses in the intertidal brown alga Fucus distichus. Ecology 69:655-663

Van Alstyne KL (1995) Comparison of three methods for quantifying brown algal polyphenolic compounds. J Chem Ecol 21:45-58

Van Alstyne KL, McCarthy JJ, Hustead CL, Kearns LJ (1999) Phlorotannin allocation among tissues of northeastern Pacific kelps and rockweeds. J Phycol 35:483-492

Van Alstyne KL, Pelletreau KN (2000) Effects of nutrient enrichment on growth and phlorotannin production in Fucus gardneri embryos. Mar Ecol Prog Ser 206:33-43

Van Alstyne KL, Dethier, MN, Duggins DO (2001a) Spatial patterns in macroalgal chemical defenses. In: McClintock JN, Baker BJ (eds) Marine chemical ecology. CRC Press, Boca Raton, FL, p 301-324

Van Alstyne KL, Whitman SL, Ehlig JM (2001b) Differences in herbivore preferences, phlorotannin production, and nutritional quality between juvenile and adult tissues from marine brown algae. Mar Biol 139:201-210

Waterman PG, Mole S (1994) Analysis of phenolic plant metabolites. Blackwell Scientific Publications, Oxford

Winter FC, Estes JA (1992) Experimental evidence for the effects of polyphenolic compounds from Dictyoneurum californicum Ruprecht (Phaeophyta: Laminariales) on feeding rate and growth in the red abalone Haliotus rufescens Swainson. J Exp Mar Biol Ecol 155:263-277

Yates JL, Peckol P (1993) Effects of nutrient availability and herbivory on polyphenolics in the seaweed Fucus vesiculosus. Ecology 74:1757-1766 